\title{
OBRNUTI FAKTORING - ALTERNATIVNI KREDITNI KANAL
}

\author{
Aleksandra Bradić-Martinovićił ${ }^{1 \star}$ Nemanja Nedović ${ }^{2}$ \\ ${ }^{1}$ Institut ekonomskih nauka, Zmaj Jovina 12, Beograd, Srbija \\ ${ }^{2}$ Beogradska bankarska akademija, Zmaj Jovina 12, Beograd, Srbija
}

\begin{abstract}
Apstrakt:
Nakon ekonomske i finansijske krize koja je pogodila svetsku ekonomiju 2007/08. godine, razvijene zemlje su uvidele potrebu za novim instrumentima za finansiranje i kreditiranje malih i srednjih preduzeća, imajući u vidu da ona predstavljaju dominantni oblik u privredama tih zemalja. Koncept finansiranja lanca snabdevanja kreiran je sa posebnim osvrtom na pokrivanje svih pojedinačnih faza i potreba učesnika u okviru lanca snabdevanja. On predstavlja evolutivni iskorak iz postojećih formi finansiranja, sa ciljem stvaranja novih izvora finansiranja na osnovu procesa lanca snabdevanja i transakcija koje se realizuju u okviru ovog lanca. Najpopularniji instrumenti su faktoring i forfeting, ali se tokom proteklih 15 godna pojavio i instrument pod nazivom obrnuti faktoring. Ovaj rad bavi se definisanjem pojma i procesa obrnutog faktoringa, kao i prednostima koje donosi učesnicima. Obrnuti faktoring nalazi se u ponudi finansijskih institucija u Srbiji, ali su prve transakcije realizovane tek u protekle dve godine.
\end{abstract}

\author{
Ključne reči: \\ faktoring, \\ finansiranje, \\ faktor, \\ mala i srednja preduzeća, \\ Srbija.
}

\begin{abstract}
Zahvalnost:
Ovaj rad je deo istraživačkih projekata pod šiframa 47009 (Evropske integracije i društveno ekonomske promene privrede EU) i 179015 (Izazovi i perspektive strukturnih promena u Srbiji: Strateški pravci ekonomskog razvoja i usklađivanje sa zahtevima EU), finansiranih od strane Ministarstva za nauku i tehnološki razvoj Republike Srbije.
\end{abstract}

\section{UVOD}

U savremenom ekonomskom okruženju koje karakterišu brojni izazovi, preduzećima je sve teže da pristupe novčanim fondovima putem tradicionalnih kanala zaduživanja. Sa druge strane, neometani rad i napredovanje malih i srednjih preduzeća u velikoj meri zavisi od solidnih novčanih tokova gotovine. Ukoliko se pojave izvesne turbulencije u ovim tokovima, posledice po preduzeća mogu biti ograničen rast, ali i nelikvidnost. Prema podacima (ACCA, 2014) oko 80\% B2B transakcija oslanjaju se na kreditne uslove u nekoj formi, a krediti predstavljaju oko $37 \%$ ukupne poslovne imovine. Uprkos dobro razvijenom kreditnom tržištu, preduzeća suočena sa izazovima visokih kamatnih stopa i nedovoljnog kreditnog potencijala, pronalaze nove načine finansiranja. Jedan od načina je primena finansiranja lanca snabdevanja (Supply Chain Finance). Ovaj koncept predstavlja odgovor tržišta na pojavu globalne nelikvidnosti, koja je u međunarodnim okvirima izazvana svetskom ekonomskom krizom i internacionalizacijom i globalizacijom poslovanja i poslovnih tokova. Razvoj napredne tehnologije za praćenje i kontrolu aktivnosti koji se realizuju u fizičkom lancu ponude omogućuje i automatizaciju i pokretanje opcija finansiranja lanca snabdevanja.

Koncept finansiranja lanca snabdevanja oslanja se na niz raspoloživih instrumenata, od kojih su najpoznatiji faktoring i forfeting. Međutim, osim navedena dva, u poslednjih petnaest godina razvija se i instrument koji je sličan faktoringu, ali je namenjen kupcima koji koriste likvidnost finansijske institucije za podmirenje dugova - obrnuti faktoring.
Cilj ovog rada je da upotpuni domaću literaturu na temu savremenih finansijskih instrumenata i da istakne značaj i mogućnosti koje preduzeća mogu da koriste putem obrnutog faktoringa. U radu je prvo predstavljen koncept finansiranja lanca snabdevanja, a zatim je predstavljen model obrnutog faktoringa. Definisan je sam proces, kao i opipljive i neopipljive prednosti koje imaju svi učesnici u poslu. Predstavljena su i tri, do sada razvijena modela obrnutog faktoringa (obrnuti faktoring, međunarodni obrnuti faktoring i integrisana radna kapitalna platforma). U poslednjem delu rada navedeni su statistički podaci i trendovi u ovoj oblasti i mogućnosti uvođenja ovog instrumenta u privredni sistem Srbije.

\section{FINANSIRANJE LANCA SNABDEVANJA}

Finansiranje lanca snabdevanja može da se definiše kao upotreba finansijskih instrumenata, prakse i tehnologije sa ciljem optimizacije upravljanja obrtnim sredstvima i likvidnošću koji su povezani sa lancem snabdevanja i procesima saradnje sa poslovnim partnerima, dobavljačima i kupcima (EBA, 2013). Drugim rečima, finansiranje lanca snabdevanja podržava održavanje fizičkog lanca snabdevanja.

Finansiranje lanca snabdevanja predstavlja evolutivni iskorak iz postojećih formi finansiranja trgovine, sa ciljem stvaranja novih izvora finansiranja na osnovu procesa lanca snabdevanja i transakcija koje se realizuju u okviru ovog lanca.

Osnovna ideja koja se nalazi u pozadini ovog koncepta odnosi se na potrebu za obezbeđenjem neometanog paralelnog protoka robnih i novčanih tokova i eventualno popunjavanje 
gepova koji se mogu pojaviti. Ključna prednost koja se javlja kao posledica primene finansiranja lanca snabdevanja je promena fokusa koji su banke imale u dosadašnjem finansiranju preduzeća, a to je finansiranje pojedinih potreba (obrtni kapital, likvidnost i slično) i otvaranje mogućnosti za pokrivanje celokupnog lanca snabdevanja (Kasavica, 2014). Na taj način prednost imaju i preduzeća i banke. Preduzeća, pre svega, dobijaju pristup jeftinijem finansiranju obrtnog kapitala, što im omogućuje da poprave svoj tok gotovine i pozajmica, jer ne moraju da koriste standardne kreditne linije. Banke imaju priliku da poprave kvalitet svojih portfolija, jer dobijaju bolji uvid u potrebe i klijenata i njihovih partnera. Osim toga, imaju mogućnost da pristupaju novim grupama dobavljača i na taj način vrše unakrsnu prodaju, što im obezbeđuje približavanje većem broju klijenata.

Finansiranje lanca snabdevanja podrazumeva čitav spektar instrumenata. U Tabeli 1 predstavljeni su instrumenti koji se koriste za finansiranje, a pored osnovnih uključeni su i pomoćni.

Tabela 1. Instrumenti finansiranja lanca snabdevanja

\begin{tabular}{|c|c|}
\hline \multicolumn{2}{|c|}{ FINANSIRANJE LANCA SNABDEVANJA } \\
\hline Obaveze & Potraživanja \\
\hline $\begin{array}{l}\text { - Obrnuti faktoring } \\
\text { - Dinamički diskont }\end{array}$ & $\begin{array}{l}\text { - Otkup potraživanja } \\
\text { - Diskontovanje faktura } \\
\text { - Faktoring } \\
\text { - Forfeting }\end{array}$ \\
\hline $\begin{array}{l}\text { Ostali instrumenti } \\
\text { finansiranja lanca } \\
\text { snabdevanja }\end{array}$ & Pomoćni \\
\hline $\begin{array}{l}\text { - Finansiranje izvoznika } \\
\text { na bazi narudžbenice } \\
\text { uvoznika } \\
\text { - Finansiranje na bazi } \\
\text { zaliha proizvoda }\end{array}$ & $\begin{array}{l}\text { - Dokumentarno finansiranje } \\
\text { trgovine } \\
\text { - Obaveze plaćanja banaka } \\
\text { - Kreditiranje bazirano na } \\
\text { imovini } \\
\text { - Plaćanja i berza deviza (FX) }\end{array}$ \\
\hline
\end{tabular}

Izvor: EBA. (2013).

Instrumenti koji se nalaze na strani potraživanja, poput faktoringa i forfetinga su već masovno zastupljeni i popularni načini prevazilaženja ograničenja standardnih bankarskih kredita i mala i srednja preduzeća ih koriste u sve većoj meri, kao što je prikazano na Grafiku 1, ali instrumenti koji se nalaze na strani obaveza još uvek su u fazi razvoja i otpora na strani tražnje.

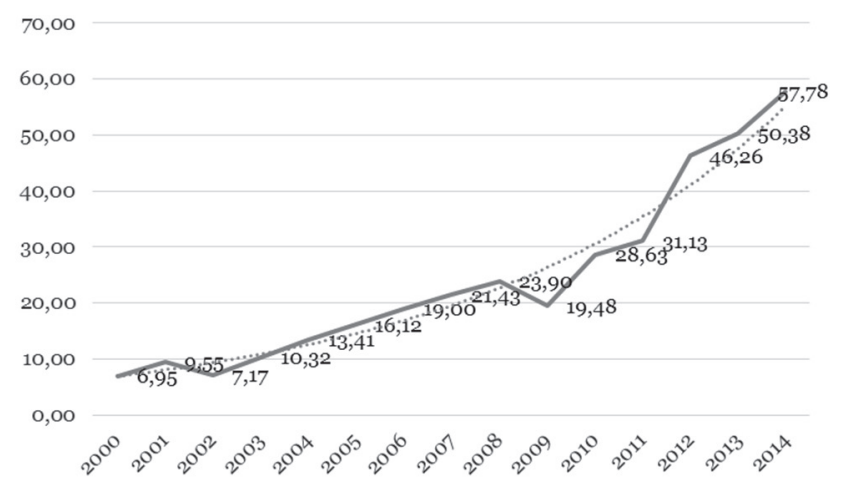

Grafik 1. Obim faktoring usluga u zemljama $\mathrm{FCI}^{\star}$

Izvor: https://fci.nl/en/about-factoring/statistics, pristup 01.10.2015. * FCI zemlje članice najveće svetske faktoring mreže Factors Chains International
Prema rezultatima istraživanja Evropske komisije i Evropske centralne banke, na osnovu upitnika, zaključeno je da je čak 37\% preduzetnika koristilo faktoring za finansiranje nekog vida poslovanja. Uprkos izrazitom rastu ove vrste usluge, ona i dalje nije dovoljno zastupljena. Ostale usluge finansiranja lanca snabdevanja, na žalost, imaju još manji udeo u ukupnom finansiranju malih i srednjih preduzeća u svetu.

U narednom delu rada bavićemo se detaljno uslugom obrnutog faktoringa.

\section{OBRNUTI FAKTORING}

Obrnuti faktoring predstavlja, kao što i sam naziv sugeriše, varijaciju osnovne usluge faktoringa. Faktoring je finansijski instrument kojim faktor (banka ili faktoring kompanija) finansira preduzeće na osnovu budućih (nedospelih) potraživanja proisteklih iz prodaje roba ili usluga na domaćem ili inostranom tržištu. U suštini predstavlja otkup tuđih potraživanja tj. finansiranje putem faktoringa predstavlja specifičan oblik pribavljanja sredstava i to putem prodaje potraživanja (Erić et al., 2012).

Kao varijacija osnovne usluge, obrnuti faktoring je po svojim osobinama identičan faktoringu, s tim što se ovom uslugom finansiraju obaveze koje preduzeća imaju prema dobavljačima, a ne prema kupcima. Obrnuti faktoring, zapravo predstavlja posebnu vrstu faktoringa koji podrazumeva sklapanje ugovara između „faktora i dužnika iz ugovora o prodaji robe ili pružanja usluga u zemlji i inostranstvu, na osnovu koga faktor, preuzimanjem faktura od dužnika, preuzima njegovu obavezu plaćanja prema poveriocima, a ima pravo naplate od dužnika u roku iz ugovora o prodaji robe ili pružanja usluga u zemlji i inostranstvu“ (Factor Centar, 2015). Da bi se realizovala navedena transakcija dužnik mora da obezbedi saglasnost od strane poverioca.

U praktičnoj realizaciji usluge obrnutog faktoringa pružalac usluge, odnosno faktor obračunava eskont, koji se računa za period između otkupa i dospeća faktura. Da bi posao bio realizovan preduzeće mora iznos eskonta da unapred uplati. Nakon toga faktor uplaćuje dobavljaču odobreni iznos finansiranja.

Najjednostavniji način da se predstavi i razume usluga obrnutog faktoringa jeste pomoću grafičkog prikaza. Na Grafiku 2 predstavljeni su tokovi robe i novca u slučaju transakcija zasnovanih na obrnutom faktoringu.

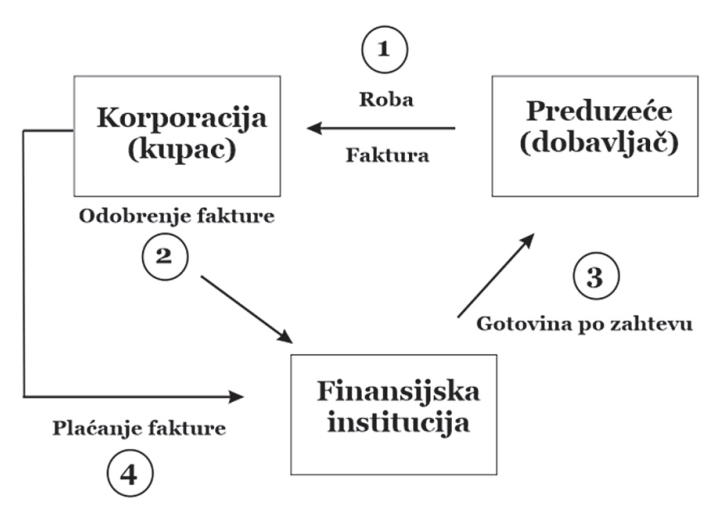

Grafik 2. Mehanizam obrnutog faktoringa Izvor: Seifert \& Seifert (2009). 
Na grafiku je predstavljena struktura i redosled događaja u transakciji obrnutog faktoringa. Nakon što malo ili srednje preduzeće - dobavljač primi nalog za isporuku robe od korporativnog klijenta i izda fakturu (1), korporacija - kupac registruje odobrenje računa u saradnji sa odgovarajućom finansijskom institucijom (2). Ukoliko malo ili srednje preduzeće ima potrebu može da ubrza protok novca (3) odnosno da naplati iznos faktura od finansijske institucije (uz eskont), a zatim će finansijska institucija naplatiti pun iznos faktura od korporativnog klijenta (4).

Upravo je najveća prednost obrnutog faktoringa u tome što preduzeće ima mogućnost da značajno ranije izmiri plaćanja prema dobavljačima. To omogućuje stvaranje boljih poslovnih odnosa sa dobavljačima, a kao posledica toga javlja se mogućnost ugovaranja novih poslova po značajno povoljnijim uslovima nabavke.

Praktično posmatrano, razvoj usluge obrnutog faktoringa, kao jedne od usluga iz palete finansiranja lanca snabdevanja zavisi, pre svega, od obima zainteresovanih korisnika. Međutim, izvesno je da prethodno navedenom mehanizmu svaki od učesnika ima određene koristi. Koristi se mogu podeliti na opipljive i neopipljive.

Opipljive koristi obrnutog faktoringa u slučaju dobavljača ogledaju se u tome što se redukuje broj dana koji je potreban da se izmire obaveze, redukuju se obavezne naknade, redukuju se troškovi ekvivalentne linije finansiranja i redukuju se marginalni troškovi obezbeđenja osiguranja likvidnosti. Kupci vide svoje opipljive koristi u produženju broja dana potrebnih da se izmire obaveze i u rabatima koje dobija od institucije koja obezbeđuje sredstva.

Osim opipljivih koristi, učesnici imaju i niz neopipljivih koristi povezanih sa uslugom obrnutog faktoringa. Za dobavljača to su: standardizacija uslova plaćanja, unapređenje planiranja gotovine, unapređenje procesa poravnanja u slučaju neizmirenja obaveza, pouzdanost novčanih gotovinskih tokova i redukovanje deviznog rizika. Za kupce to su: unapređenje procesa poravnanja u slučaju neizmirenja obaveza, oslobađanje kreditnih linija, izbegavanje oportunitetnih troškova propuštenih investicija, upravljanje elektronskim računima (fakturama), redukovanje rizika nedovoljnih zaliha i redukovanje deviznog rizika (EBA, 2013).

Hurtez i Salvadori (2010), međutim, tvrde da formalni mehanizam finansiranja lanca snabdevanja nije, do današnjeg dana, dostigao odgovarajući nivo standardizacije i da zbog toga nije masovno prihvaćen. Ovi autori ideju čak nazivaju i mitom. Polazna osnova ovog koncepta nalazi se u ideji globalnog povezivanja (dobavljača i kupaca), kao rezultat dosadašnjeg razvoja mogu se razlikovati tri osnovna modela finansiranja lanca snabdevanja.

Prvi model je uveden 1999. godine, a predstavljao je kombinaciju finansiranja domaće trgovine sa upravljanjem lancem snabdevanja kroz inovativni finansijski aranžman - domaći obrnuti faktoring. U najranijem obliku obrnuti faktoring je funkcionisao samo u okviru nacionalnih tokova, a dominantno je bio u ponudi automobilskoj industriji. Drugi model međunarodni obrnuti faktoring pojavio se kada je određen broj velikih kompanija započeo potragu za dobavljačima sirovina među malim i srednjim preduzećima u inostranstvu. U ovoj fazi ključno je bilo obezbediti razvoj tehnološke platforme koja je imala dve inovativne funkcije. Prva funkcija je podrazumevala mogućnost da se povežu sve zainteresovane kompanije širom sveta, a druga je bila da se obezbede brojni kreditori koji će biti u stanju da se povežu i takmiče na tržištu novca, sa ciljem obezbeđenja najnižih troškova finansiranja potraživanja, kako bi privukli što veći broj dobavljača.

Međutim, uprkos svim inovacijama koncept finansiranja lanca snabdevanja nije opravdao očekivanja u potpunosti. Jedan od glavnih razloga je taj što u mnogim zemljama zakonodavstvo ne prepoznaje kategoriju elektronske fakture (e-invoice) i drugih elektronskih dokumenata kao zakonski obavezujućih. Drugi razlog je taj što su sredinom prve decenije dvadeset prvog veka niski troškovi kapitala praktično eliminisali marginalnu prednost kreditne arbitraže između velikih kompanija u ulozi kupaca i malih i srednjih preduzeća u ulozi dobavljača. Konačno, izgradnja i razvoj pomenute platforme ispostavio se kao previše skupa. Kao rezultat svega navedenog pojavio se i treći model koji podrazumeva integraciju delova finansijskog lanca snabdevanja "sa kraja na kraj”, potpunu automatizaciju nabavke i plaćanja u slučaju kupaca i prodaje i naplate u slučaju dobavljača. Integracija nabavke, fakturisanja i finansiranja u okviru jedne platforme predstavljalo bi punu konvergenciju upravljanja gotovinom i finansijama u trgovini.

Kao primere uspešne upotrebe obrnutog faktoringa možemo navesti kompaniju Proctor \& Gabmble koja je produžila uslove i rok plaćanja svim dobavljačima za 30 dana u okviru programa obrnutog faktoringa da bi na taj način olakšala probleme vezane za likvidnost dobavljača. Unilever je koristio sličan pristup i uspeo za tri godine da redukuje obrtni kapital za 2 milijarde dolara. I Philips je upotrebom obrnutog faktoringa uspeo da obezbedi status preferencijalnog kupca u odnosu na svoje dobavljače, tako što je redukovao rizik od poremećaja u lancu snabdevanja (Serrano i Lekkakos, 2015).

\section{POTENCIJAL ZA RAZVOJ TRŽIŠTA U SRBIJI}

Tržište obrnutog faktoringa u Srbiji je nastalo donošenjem Zakona o faktoringu 2013. godine (Sl. glasnik RS, 2014). U zakonu je definisano sve što je od značaja za obavljanje faktoring posla uopšte, a kao posebna vrsta faktoringa definiše se obrnuti faktoring. Međutim, nije poznato koje kompanije, od onih koje imaju dozvolu za obavljanje poslova faktoringa, pružaju ovaj oblik finansiranja.

Na osnovu izveštaja koje objavljuje Privredna komora Beograda (2014), a dobijenom na osnovu ankete, koji sastavlja sekcija za faktoring vidi se da je ukupan promet ovog oblika faktoringa u 2013. godini bio 17.754.000 dinara. Ukoliko ovaj iznos uporedimo sa ukupnim prometom faktoringa u Srbiji u 2013. godini koji je iznosio 679.248.122,67 videćemo da se radi o izuzetno malom udelu. Drugim rečima najverovatnije je reč o par ugovora o obrnutom faktoringu.

$\mathrm{Na}$ osnovu iskustava drugih zemalja u kojima se u određenim granama procenat finansiranja putem obrnutog faktoringa kreće i do 25\% (ACCA, 2014) može se zaključiti da postoji veliki potencijal za razvoj ovog oblika finansiranja u Srbiji. Verovatno najvažnija stvar na polju razvoja ovog vida finansiranja je rešenost onih institucija koje se bave faktoringom da ponude uslugu obrnutog faktoringa. Međutim, kako je najveća faktoring kuća u Srbiji Prvi Faktor d.o.o. obustavio sve poslove finansiranja sa najavom likvidacije do kraja godine može se očekivati značajan pad obima finansiranja putem faktoringa u 2015. godini. Na osnovu ovoga i evidentnog smanjenja aktivnosti drugih kompanija i loše finansijske discipline, ne može se očekivati ozbiljan rast ovog tržišta u naredih nekoliko godina.

Osim toga, u procesu razvoja domaćeg tržišta moraju se imati u vidu i rezultati istraživanja na temu tržišnog prihvatanja 
obrnutog faktoringa koje je objavljeno 2015. godine (Dello Iacono et al., 2015) i koje je ukazalo na to da je uvođenje i širenje obrnutog faktoringa moguće samo pod posebnim tržišnim uslovima. Autori navode da taj proces često može predstavljati izazov. Primera radi, promena ključnih egzogenih faktora, kao što su kamatne stope ili obim prometa, mogu dovesti do stagnacije ovog tržišta, bez obzira što promena navedenih faktora dovodi do poboljšanja ostalih promenljivih na tržištu. Zbog toga, osnovna pretpostavka da svi učesnici u poslu imaju povoljan ishod (win-win situacija) ne mora uvek da bude ispunjena. Dešava se i da se direktna korist učesnika menja tokom vremena, ukoliko se promene uslovi na tržištu. Zbog toga je veoma važno da se ovaj koncept uvede tek onda kada se konceptualno usavrši do te mere da predvidi sve moguće ishode i načine na koje će se učesnici zaštiti od nepovoljnih promena.

\section{ZAKLJUČAK}

Dosadašnja empirijska istraživanja pokazala su da je obrnuti faktoring dobar način da se prevaziđu problemi onih učesnika u lancu snabdevanja u zemljama koje imaju loš informacioni sistem vezan za kreditne rejtinge (Klapper, 2006). Međutim, upravo u tim ekonomijama postoje i velika ograničenja za tržišno prihvatanje ovog koncepta, a pre svega tehnološka (npr. nepostojanje ili zakonsko neprepoznavanje elektronskih faktura).

Važno je navesti i da pojedini autori (Serrano \& Lekkakos, 2015) smatraju da postoji niz rizika povezanih sa funkcionisanjem samog mehanizma obrnutog faktoringa. Prvo, mehanizam radi dobro dok kupci plaćaju na vreme, međutim poslednja kriza je pokazala da i kompanije sa visokim kreditnim rejtingom mogu propasti. Ukoliko se to desi i ako kupac ne ispuni svoje obaveze plaćanja, finansijska institucija koja pruža uslugu obrnutog faktoringa podnosi sav rizik, a to može dovesti i do propasti slabijih institucija. Hipotetički posmatrano, ukoliko bi ova vrsta posla bila masovno popularna na tržištu, mogla bi kao posledica propasti da se javi i kriza. Zbog toga postoji velika odgovornost na strani banaka i drugih finansijskih institucija sa ciljem utvrđivanja rizika svakog potencijalnog korisnika ove usluge.

Osim toga, kompanije koje koriste ovu vrstu usluge moraju da budu svesne i rizika da time mogu poslati signal o svojoj slabosti na tržištu i time ugroze svoju pregovaračku poziciju na tržištu ili ograniče opcije za druge investicione mogućnosti.
Uprkos navedenim rizicima smatra se da je model obrnutog faktoringa koristan u onim situacijama kada novčani tokovi nisu u stanju da isprate realne ekonomske tokove lanca snabdevanja.

\section{LITERATURA}

ACCA. (2014). Accountants for Business - A Study of the Business case for Supply Chain Finance. London: The Association of Chartered Certified Accountants.

Bryant, C., \& Camerinelli, E. (2012). Supply Chain Finance. Paris: Euro Banking Association.

Dello Iacono, U., Reindorp, M., \& Dellaert, N. (2014). Market adoption of reverse factoring. International Journal of Physical Distribution \& Logistics Management, 45(3), 286-308. doi:10.1108/IJPDLM-10-2013-0258.

EBA. (2013). Market Guide on Supply Chain Finance. Paris: Euro Banking Association.

Erić, D., Beraha, I., Đuričin, S., Kecman, N., \& Jakšić, B. (2012). Finansiranje malih i srednjih preduzeća u Srbiji. Beograd: Privredna komora Srbije, Institut ekonomskih nauka Beograd.

Factoring Chan International. (2015). About Factoring. Preuzeto 01. oktobra 2015. sa https://fci.nl/en/about-factoring/statistics

Faktor Centar. (2015). Obrnuti faktoring. Preuzeto 5. oktobra 2015. sa http://centarfaktor.rs/portfolio/obrnuti-faktoring/

Hurtez, N., \& Salvadori, G.M. (2010). Suplly Chain Finance: From Myth to Reality. London: McKinsey on Payments.

Kasavica, P. (2014). Finansiranje lanca snabdevanja. Bankarstvo, 3/2014, 96-127.

Klapper, L. (2006). The Role of Factoring for financing Small and Medium Enterprises. Journal of Banking \& Finance 30, 3111-3130.

Privredna komora Beograda. (2013). Rezultati ankete o prometu faktoringa za 2013. godinu. Preuzeto 17. oktobra 2015. sa http://www.kombeg.org.rs/Slike/UdrFinansijskeOrganizacije/Faktoring/2014/februar/Rezultati\%20ankete\%20 o\%20prometu\%20faktoringa\%20za\%202013.pdf.

Seifert, R., \& Seifert, D. (2009). Supply Chain Finance - What's it worth? Lausanne: IMD.

Serrano, A., Lekkakos, S. (2015). Will Reverce Factoring Caouse the Next Financial Bubble? Preuzeto 10. oktobra 2015. sa http://ww2.cfo.com/credit/2015/01/will-reverse-factoring-cause-next-financial-bubble/

Službeni glasnik Republike Srbije. (2013). Zakon o faktoringu Republike Srbije. Službeni glasnik RS, br. 62/13.

\section{REVERSE FACTORING - ALTERNATIVE CREDIT CHANNEL}

\section{Abstract:}

Upon the economic and financial crisis that affected the world economy in 2007/2008., the developed countries have become aware of the necessity to develop new funding and crediting instruments for small and medium-sized enterprises, bearing in mind that they are the prevailing form in the economies of those countries. The concept of supply chain financing has been developed bearing in mind all individual phases and needs of the participants. It represents the evolutionary breakthrough from traditional forms of financing with the aim of creating new funding sources based on the supply chain process and transactions carried out within it. The most popular instruments are factoring and forfaiting, as well as reverse factoring that has emerged over the last 15 years. This paper aims to provide the definition of reverse factoring and its benefits for the participants. Even though reverse factoring is available at financial institutions in Serbia, the first such transactions have been carried out over the last two years.

Key words:
factoring,
funding,
factor,
small and medium-sized enterprises,
Serbia.

